\title{
The association between level of maternal serum leptin in the third trimester and the occurrence of moderate preterm labor
}

\author{
Fereshteh Fakor ${ }^{1}$, Seyedeh Hajar Sharami', Forozan Milani', Fariba Mirblouk ${ }^{1}$, Sodabeh Kazemi ${ }^{1}$, Davoud Pourmarzi², \\ Hannan Ebrahimi ${ }^{1}$, Seyedeh Fatemeh Dalil Heirati ${ }^{1}$ \\ ${ }^{1}$ Reproductive Health Research Center, Department of Obstetrics and Gynecology, Guilan University of Medical Sciences, \\ Rasht, Iran \\ ${ }^{2}$ Reproductive Health Research Center, Department of Epidemiology, Guilan University of Medical Sciences, Rasht, Iran
}

Abstract

Objective: We aimed to investigate the relationship between the level of maternal serum leptin and the occurrence of moderate preterm labor. Material and Methods: This was a case control study conducted on pregnant women referred to Al- Zahra Hospital in Rasht, north of Iran in 2013. Cases included 30 moderate preterm delivering women and 30 control pregnant women with the same gestational age. The maternal serum leptin was measured for each mother at the time of entering the study.

Results: The mean serum leptin in the control group (56.66 \pm 34.18$)$ was significantly higher than the preterm (33.65 \pm 16.70$)$ group. There were no significant differences between the groups in terms of body mass index and age. Logistic regression revealed that age and body mass index did not have a significant relationship to moderate preterm birth. However, an increased leptin level as low as 1 microgram per liter was associated with the risk of moderate preterm birth incidence (OR: 0.973, CI: 0.948-0.997).

Conclusion: Higher levels of leptin in pregnant women are associated with a decreased risk of moderate preterm birth. Further investigations are recommended with a larger sample size. (J Turk Ger Gynecol Assoc 2016; 17: 182-5)

Keywords: Preterm birth, leptin, delivery, pregnancy

Received: 3 July, 2016 Accepted: 16 October, 2016

\section{Introduction}

Preterm birth is a serious health problem associated with neonatal morbidity and mortality (1). Preterm birth is the leading cause of neonatal mortality and the second prevalent cause of mortality in children aged less than 5 years (2). Additionally, the rate of death by other causes, such as neonatal infections, in preterm neonates are higher than term neonates (3).

The World Health Organization defined preterm labor as live birth before 37 weeks of gestation. Preterm birth is classified to three subgroups as defined by gestational age: extremely preterm $(<28$ weeks), very preterm $(28-<32$ weeks), and moderate preterm $(32-<37$ completed weeks of gestation) (4). Moderate preterm birth includes late preterm birth (34-<37 completed weeks of gestation). The occurrence of preterm birth was reported as $5-18 \%$, worldwide. The prevalence of preterm labor in Iran has been estimated to be $10-15 \%$ of deliveries $(4,5)$. Recent strategies to avert preterm labor are used to prevent mechanisms that increase the frequency and severity of uterine contractions (6). Although, various tocolytic drugs are commonly used in this regard, there is no consensus on which is best (7).

Leptin is a peptide and a tocolytic factor hormone. It is the product of the ob gene with a 16 kda molecular weight, 167 amino acids long, and a half-life of 25 (8-10). During pregnancy, leptin is secreted from placental trophoblasts and enters from the placenta to the fetal and maternal body. Leptin can have a significant role on fetal growth and development, angiogenesis, and hematopoiesis $(8,11)$. Leptin levels increase during pregnancy, in which the lowest level can be assessed in the first trimester, and the highest during the second trimester. A plateau is noted in the third trimester of pregnancy $(8,12)$.

Results have shown that leptin can affect physiological processes such as glucose metabolism and immune system responses $(9,13,14)$. Dotsch et al. (15) mentioned that the mean leptin level in term neonates was 6-fold higher than preterm neonates.

According to previous investigations, various factors, such as maternal body mass index (BMI), maternal age, and smoking cigarettes could influence the umbilical leptin levels (16). Additionally, there was a linear relationship between leptin 
level and the body lipid content (17). Generally, obese pregnant women had a lower risk of preterm birth and had a higher rate of post term birth compared to normal weight mothers (18). Laboratory studies indicated that the myometrium in obese women had a lower ability to contract and this issue might be caused by a higher level of leptin $(10,19)$.

As there are limited investigations on the level of leptin as a predictor for preterm birth, most studies were cross-sectional and they assessed leptin levels during birth. In this study, we aimed to investigate the relationship between levels of maternal serum leptin and the incidence of moderate preterm labor.

\section{Material and Methods}

\section{Setting and patients}

A case control study was conducted on pregnant women at $\mathrm{Al}$ Zahra Hospital in Rasht, north of Iran in 2013. The study was approved by the Ethical Committee of the Guilan University of Medical Sciences (Number: 1920251601, Date: 7.13.2013), and all participants provided written informed consent. The study was a pilot study to understand the relationship of maternal serum leptin levels and the incidence of moderate preterm labor. The cases included 30 pregnant women at 30-34 weeks of gestation without rupture of the membrane. They were hospitalized with a diagnosis of moderate preterm labor (uterine contractions with at least three centimeter dilation and 80\% effacement). The gestational age was estimated by ultrasound reports ( $<20$ weeks) and the date of the last menstrual period. Women were excluded if they had known associating factors such as multiple pregnancy, rupture of the membrane, known vaginal infection, cervical incontinence (cervix length less than 30 millimeter as measured by ultrasound), and conditions affecting leptin levels such as diabetes, polycystic ovarian syndrome (PCOS, based on the Rotterdam criteria including menstrual disorders, PCOS morphology, and hyperandrogenism), preeclampsia (blood pressure $\geq 140 / 90$ and proteinuria after 20 weeks of gestation), corticosteroid therapy, and cytotoxic drug use.

For each case, a gestational age-matched control was included in the study. The control group included pregnant women that attended the hospital prenatal clinic for routine prenatal care at 30-34 weeks of gestation. They did not mention the symptoms and signs of preterm delivery. If women in the control group delivered before 34 weeks of gestational age, we would consider them as a case and would find a control who matched, in terms of gestational age, at the time of entering into the study. In this study, we did not observe this type of participant in the control group. Data including leptin level, age, weight, height, BMI, neonatal weight, and gestational age at delivery were collected.

Height was measured in standing position and weight was measured with bare feet using a standard scale. The BMI was calculated by dividing the weight $(\mathrm{kg})$ by height $\left(\mathrm{m}^{2}\right)$. Normal, overweight, and obese mothers were identified based on BMI values of $<25,25-30$, and $\geq 30$, respectively.

\section{Leptin measurement}

Five cc blood samples were drawn from each participant and were sent to the specific laboratory at 30-34 weeks of gestation. A specific human leptin LBN kit (LDN, Germany) using the enzyme-linked immunosorbent assay (ELISA) method was used to measure serum leptin levels. The measurement was performed based on the manufacturers' instruction. All blood samples were drawn and analyzed in one pre-specified laboratory.

\section{Statistical analysis}

Statistical analysis was done using SPSS software version 21.0 (SPSS Inc.; Chicago, IL, USA). Data was reported as mean and standard deviation. The independent $t$ test was used for comparing means between the two groups. Multiple logistic regression analysis was applied to investigate the predicting effect of leptin level on incidence of preterm delivery. $P$ values less than 0.05 were considered statistically significant and a $95 \%$ confidence interval was noted.

\section{Results}

The mean age in the case group $(27.83 \pm 5.89)$ was higher than the control group $(25.33 \pm 4.66)$, but the difference was not statistically significant $(\mathrm{p}=0.074)$. In the control group, BMI $(p=0.017)$, gestational age at delivery $(p=0.0001)$, and neonatal weight $(p=0.028)$ were significantly higher than the case group. None of the women were smokers. The mean level of leptin in the control group $(56.66 \pm 34.18)$ was significantly higher than the case group $(33.65 \pm 16.70)(p=0.002)$, as shown in Table 1 . Logistic regression revealed that age and BMI did not have a significant relationship to preterm birth incidence. However, increasing the leptin level to 1 microgram per liter could decrease the risk of moderate preterm birth by $2.7 \%$ (Table 2 ).

\section{Discussion}

According to the results, a higher level of leptin in pregnant women could decrease the risk of birth before 34 weeks of

Table 1. Comparing demographic/reproductive characteristics between the case and control groups

\begin{tabular}{|l|c|c|c|}
\hline Variables & $\begin{array}{c}\text { Case group } \\
(\mathbf{n = 3 0 )}\end{array}$ & $\begin{array}{c}\text { Control group } \\
(\mathbf{n = 3 0 )}\end{array}$ & $\begin{array}{c}\mathbf{p} \\
(\mathbf{t} \text { test) }\end{array}$ \\
\hline Age (year) & $27.83 \pm 5.89$ & $25.33 \pm 4.66$ & 0.074 \\
\hline Body Mass Index $\left(\mathrm{kg} / \mathrm{m}^{2}\right)$ & $27.59 \pm 5.78$ & $31.10 \pm 5.28$ & 0.017 \\
\hline $\begin{array}{l}\text { Gestational age at } \\
\text { delivery (week) }\end{array}$ & $32.19 \pm 1.13$ & $36.24 \pm 2.21$ & 0.0001 \\
\hline Neonatal weight (gr) & $2293.47 \pm 813.51$ & $2724.83 \pm 664.86$ & 0.028 \\
\hline Leptin level $(\mu \mathrm{g} / \mathrm{L})$ & $33.65 \pm 16.70$ & $56.66 \pm 34.18$ & 0.002 \\
\hline
\end{tabular}

Table 2. Logistic regression analysis to reveal the effects of maternal age, BMI, and leptin level on moderate preterm birth incidence

\begin{tabular}{|l|c|c|}
\hline Variables & OR (95\% Confidence Interval) & p \\
\hline Age $($ year $)$ & $1.093(0.975-1.225)$ & 0.127 \\
\hline Body Mass Index $\left(\mathrm{kg} / \mathrm{m}^{2}\right)$ & $0.919(0.820-1.030)$ & 0.146 \\
\hline Leptin level $(\mu \mathrm{g} / \mathrm{L})$ & $0.973(0.948-0.997)$ & 0.031 \\
\hline OR: odds ratio & & \\
\hline
\end{tabular}


gestation. In this study, maternal age and BMI did not have significant effects on the risk of moderate preterm delivery. Leptin might change the pregnancy outcome by affecting the cytokines balance in the feto-placental unit. Furthermore, leptin could affect the activity of cytotrophoblast (20) and, by angiogenic activity, might affect placental growth (21). Some of the previous studies have shown the effect of leptin on myometrial contractions. Wuntakal et al. (10) assessed myometrial biopsies in obese women. They mentioned that access to the leptin had a protecting effect on induced myometrial contraction. They found leptin as a cause for dysfunctional labor in obese women, which led to a higher rate of cesarean section. They recommended it as a tocolytic factor that could prevent preterm birth (10). Moynihan et al. (19) assessed 18 pregnant women who underwent cesarean section after oxytocin induction. They exposed mothers to leptin and observed a decreased frequency and severity of contractions. They also reported the protecting effect of leptin on myometrial contractions (19). Laird et al. (22) assessed 53 women with a history of repeated spontaneous abortion at 5-6 and 7-8 weeks of gestation. Among them, 23 abortions, 23 term delivery, and 7 preterm births were noted. Results showed that, in both periods of assessing leptin, women with term delivery had significantly higher levels of leptin compared to women with spontaneous abortion. While slightly higher leptin was noted in term deliveries, no significant difference was noted between preterm and term groups, which might be because of the limited sample size of the preterm group. They mentioned that age and BMI had no significant effect on preterm birth, but the level of leptin could be a predictor for preterm birth (22). Shroff et al. (23) studied 1304 pregnant women in 16-27 weeks of gestation. They mentioned that maternal leptin level in term appropriate-for-gestational age infants was significantly higher than in preterm appropriatefor-gestational age infants and small for gestational age infants. This difference was noted even after controlling pre-pregnancy BMI, blood pressure disorders, and diabetes (23).

Furthermore, Palchevska et al. (24) indicated that leptin levels in 110 term neonates were higher than preterm neonates (24). Laivuori et al. (25) study on women with pre-eclampsia showed that leptin levels in pre-eclamptic women with term delivery was higher than pre-eclamptic women with preterm delivery and normal healthy women with term and preterm deliveries. Also, higher leptin levels were noted in term deliveries compared to preterm deliveries (25).

\section{Limitations}

In this study, we only assessed maternal leptin levels. It seems that leptin is a biomarker affecting preterm labor. The leptin levels in the case group were measured at a time near the delivery, which can affect our findings. Also, many socio-economic factors that can affect preterm delivery were not assessed.

In conclusion, a higher level of leptin can decrease the risk of moderate preterm birth. As leptin is secreted from lipid cells, it seems that short-term use (24 h) of leptin for postponing delivery does not have severe complications on the mothers or the fetus. Distinguishing the mechanism of tocolytic agents is recommended before they are applied and further investiga- tions are recommended to assess leptin safety and efficacy on the prevention of preterm birth.

Ethics Committee Approval: Ethics committee approval was received for this study from the ethics committee of Guilan University of Medical Sciences (Number: 1920251601, Date: 7.13.2013).

Informed Consent: Written informed consent was obtained from patients who participated in this study.

Peer-review: Externally peer-reviewed

Author Contributions: Concept - F.F., S.H.S., F.Milani; Design - F.F., S.H.S., F.Mirblouk, S.K., D.P.; Supervision - F.F., S.H.S.; Resources - F.F., S.H.S., F.Milani, F.Mirblouk, S.K.; Materials - F.F., S.H.S., F.Milani, F.Mirblouk, S.K.; Data Collection and/or Processing - D.P., H.E., S.F.D.H.; Analysis and/or Interpretation - S.H.S., D.P, H.E.; Literature Search - F.F., S.K., H.E., S.F.D.H.; Writing Manuscript - F.F., S.H.S., F.Milani, F.Mirblouk, S.K., D.P., H.E., S.F.D.H.; Critical Review - F.F., S.H.S., F.Milani, F.Mirblouk, S.K., D.P.

Acknowledgements: The authors would like to thank Dr. Hadi Hajizadeh, Ms. Afagh Hasanzadeh and Dr. Hadiseh Eghtedari for their cooperation. We gratefully thank the Vice Chancellor for research and technology of Guilan University of Medical Sciences for its collaboration.

Conflict of Interest: No conflict of interest was declared by the authors.

Financial Disclosure: The authors declared that this study has received financial support from Vice- Chancellorship of Research and technology Gulian University of Medical Sciences.

\section{References}

1. Beck S, Wojdyla D, Say L, Betran AP, Merialdi M, Requejo JH, et al. The worldwide incidence of preterm birth: a systematic review of maternal mortality and morbidity. Bull World Health Organ 2010; 88: 31-8.

2. Liu L, Johnson HL, Cousens S, Perin J, Scott S, Lawn JE, et al. Global, regional, and national causes of child mortality: an updated systematic analysis for 2010 with time trends since 2000. Lancet 2012; 379: 2151-61.

3. Lawn JE, Cousens S, Zupan J; Lancet Neonatal Survival Steering Team. 4 million neonatal deaths: when? Where? Why? Lancet 2005; 365: 891-900.

4. Organisation Wh. Preterm birth, Fact sheet $N^{\circ} 363$ Genova: World health organisation; 2015. Available from: http://www.who.int/mediacentre/factsheets/fs363/en/.

5. Blencowe H, Cousens S, Chou D, Oestergaard M, Say L, Moller A, et al. Chapter 2: 15 million preterm births: Priorities for action based on national, regional and global estimates. Born Too Soon: The Global Action Report on Preterm Birth New York: March of Dimes, PMNCH, Save the Children, World Health Organization. 2012.

6. Olson DM, Christiaens I, Gracie S, Yamamoto Y, Mitchell BF. Emerging tocolytics: challenges in designing and testing drugs to delay preterm delivery and prolong pregnancy. Expert Opin Emerg Drugs 2008; 13: 695-707.

7. James DK, Steer PJ, Weiner CP, Gonik B. High risk pregnancy: management options-expert consult: Elsevier Health Sciences; 2010.

8. Hauguel-de Mouzon S, Lepercq J, Catalano P. The known and unknown of leptin in pregnancy. Am J Obstet Gynecol 2006; 194: 1537-45.

9. Bouloumié A, Drexler HC, Lafontan M, Busse R. Leptin, the product of Ob gene, promotes angiogenesis. Circ Res 1998; 83: 1059-66.

10. Wuntakal R, Hollingworth T. Leptin-A tocolytic agent for the future? Med Hypotheses 2010; 74: 81-2.

11. Lea R, Howe D, Hannah L, Bonneau O, Hunter L, Hoggard N. Placental leptin in normal, diabetic and fetal growth-retarded pregnancies. Mol Hum Reprod 2000; 6: 763-9.

12. Helland IB, Reseland JE, Saugstad OD, Drevon CA. Leptin levels in pregnant women and newborn infants: gender differences and reduction during the neonatal period. Pediatrics 1998; 101: e12-e. 
13. Mise H, Yura S, Itoh H, Nuamah MA, Takemura M, Sagawa N, et al. The relationship between maternal plasma leptin levels and fetal growth restriction. Endocr J 2007; 54: 945-51.

14. Mantzoros CS, Moschos SJ. Leptin: in search of role (s) in human physiology and pathophysiology. Clin Endocrinol 1998; 49: 551-67.

15. Dötsch J, Nüsken KD, Knerr I, Kirschbaum M, Repp R, Rascher W. Leptin and neuropeptide $Y$ gene expression in human placenta: ontogeny and evidence for similarities to hypothalamic regulation. J Clin Endocrinol Metab 1999; 84: 2755-8.

16. Considine RV, Sinha MK, Heiman ML, Kriauciunas A, Stephens TW, Nyce MR, et al. Serum immunoreactive-leptin concentrations in normal-weight and obese humans. N Engl J Med 1996; 334: 292-5.

17. Nakao K, Nakata K, Ohtsubo N, Maeda M, Moriuchi T, Ichikawa T, et al. Association between nonalcoholic fatty liver, markers of obesity, and serum leptin level in young adults. Am J Gastroenterol 2002; 97: 1796-801.

18. Vahratian A, Siega-Riz AM, Savitz DA, Zhang J. Maternal pre-pregnancy overweight and obesity and the risk of cesarean delivery in nulliparous women. Ann Epidemiol 2005; 15: 467-74.

19. Moynihan AT, Hehir MP, Glavey SV, Smith TJ, Morrison JJ. Inhibitory effect of leptin on human uterine contractility in vitro. Am J Obstet Gynecol 2006; 195: 504-9.
20. González RR, Simón C, Caballero-Campo P, Norman R, Chardonnens D, Devoto L, et al. Leptin and reproduction. Hum Reprod Update 2000; 6: 290-300.

21. Sierra-Honigmann MR, Nath AK, Murakami C, García-Cardeña G, Papapetropoulos A, Sessa WC, et al. Biological action of leptin as an angiogenic factor. Science 1998; 281: 1683-6.

22. Laird S, Quinton N, Anstie B, Li T, Blakemore A. Leptin and leptinbinding activity in women with recurrent miscarriage: correlation with pregnancy outcome. Hum Reprod 2001; 16: 2008-13.

23. Shroff MR, Holzman C, Tian Y, Evans RW, Sikorskii A. Mid-pregnancy maternal leptin levels, birthweight for gestational age and preterm delivery. Clin Endocrinol (Oxf) 2013; 78: 607-13.

24. Palchevska SKM, Shukarova E, Aluloska N, Jakimoska M, Kocevski D, et al. Comparing Preterm and Term Newborns Serum Adiponectin and Leptin Concentrations and their Correlations with Anthropometric Parameters. Macedonian J Med Sci 2012; 5: 317-23.

25. Laivuori H GM, Collura L, Crombleholme W, Markovic N, Rajakumar A, et al. Relationships between maternal plasma leptin, placental leptin mRNA and protein in normal pregnancy, pre-eclampsia and intrauterine growth restriction without pre-eclampsia. Mol Hum Reprod 2006; 12: 551-6. 